\title{
DIRITI DE BDÈ BURÈ: UM OLHAR ECOFEMINISTA RUMO A REDISTRIBUIÇÃO E RECONHECIMENTO
}

\author{
Silvana Beline Tavares ${ }^{1}$ \\ Adriana Andrade Miranda ${ }^{2}$
}

\section{RESUMO}

Este trabalho objetiva analisar como a feitura da Ritxoko pela indígena Diriti Karajá da aldeia Bdè Burè pode ser identificada como possibilidade de manutenção da cultura e subsistência das mulheres visando a desconstrução da ortodoxia imposta pela sociedade. A discussão versa sobre a apreensão de sentidos atribuídos à mulher e a natureza a partir do Ecofeminista crítico e a busca de redistribuição e reconhecimento. A Pesquisa Bibliográfica contribuiu para a construção do trabalho com a Observação Participante, obtida pelo contato direto com os atores a partir da filmagem do documentário Diriti de Bdè Burè, que permitiu conhecer seus pontos de vista e suas perspectivas.

Palavras-chave: Ecofeminismo, mulheres indígenas, relações de gênero, redistribuição e reconhecimento.

\section{DIRITI DE BDÈ BURÈ: AN ECOFEMINIST LOOK TOWARDS REDISTRIBUTION AND RECOGNITION}

\begin{abstract}
The objective of this work is to analyze how Ritxoko 's work by indigenous Diriti Karajá from Bdè Burè village can be identified as a possibility of maintaining the culture and the subsistence of women in a perspective aimed at deconstructing the orthodoxy imposed by society. We will try to elaborate a discussion about the apprehension of the meanings attributed to women and nature from the critical Ecofeminist and the search for redistribution and recognition. The Bibliographic Research contributed to the construction of the work together with the Participating Observation, obtained by the direct contact from the filming of the documentary Diriti de Bdè Burè, where it was possible to collect information from the actors, their points of view and their perspectives.
\end{abstract}

Keywords: Ecofeminism, indigenous women, gender relations, redistribution and recognition.

\footnotetext{
${ }^{1}$ Professora Adjunta da Faculdade de Direito da Universidade Federal de Goiás; belinesilvana@gmail.com

${ }^{2}$ Professora Assistente da Faculdade de Direito da universidade Federal de Goiás; adrianaandrade@gmail.com
} 


\section{INTRODUÇÃO}

A apreensão com os problemas ecológicos e ambientais aumenta consideravelmente com o passar do tempo e desde a década de 1970 a destruição do meio ambiente tem sido discutida por feministas que associam a formas de dominação e opressão às mulheres no panorama de ampliação da política capitalista. A relação entre gênero e desenvolvimento sustentável na questão das mulheres indígenas busca levantar aspectos inerentes à situação que se estabelece entre a necessidade de subsistência e os atributos culturais e ecológicos da sustentabilidade.

Este trabalho nasce de uma inquietação gerada pela necessidade de registrar o modo de fazer Ritxoko por Diriti, uma mulher indígena do povo Karajá. Inquietação esta que gerou um documentário etnobiográfico em que mostra como Diriti, habitante da Aldeia Bdè Buré, em Aruanã / Goiás - Vale do Rio Araguaia, referência mitológica e social do povo $^{3}$ Karajá - confecciona a Ritxoko para manutenção da cultura de seu povo e de sua subsistência econômica a partir de sua luta por redistribuição e reconhecimento.

A cultura "denota um padrão de significado transmitido historicamente, incorporado em símbolos, um sistema de concepções herdadas e expressas em formas simbólicas por meio das quais os homens comunicam, perpetuam e desenvolvem seu conhecimento e suas atividades em relação a vida" (GEERTZ, 1984, p. 103). Importanos lembrar que para se pensar a cultura a que se refere este trabalho deve-se focar em questões relacionadas ao modo de ser e de viver do povo Karajá e como entendem suas próprias culturas em contraste com o entendimento de cultura construído pelo não indígena.

Importante lembrar que Ritxòkò - como representação cultural Karajá significa bonecas de cerâmica no dialeto Iny, reconhecida como patrimônio imaterial pelo Instituto do Patrimônio Histórico e Artístico Nacional (Iphan) desde 2012. Sua

\footnotetext{
${ }^{3}$ Entendemos por povo indígena a definição vigente na Convenção n. 169 da OIT e do conceito de povos e comunidades tradicionais adotado pelo Decreto n.6040 que instituiu a Política Nacional de Desenvolvimento dos Povos e Comunidades Tradicionais: Povos culturalmente diferenciados e que se reconhecem como tal, que possuem identidades étnicas específicas e formas próprias de organização social, econômica e política, bem como cosmovisões especificas e relações particulares com a terra que habitam. Sendo regidos, total ou parcialmente, por seus próprios sistemas consuetudinários ou por legislação específica.
} 
feitura essencialmente feminina passa pela preparação do barro, modelagem, queima e pintura evidenciado no documentário Diriti de Bdè Burè acima mencionado. As bonecas representam cenas do cotidiano simulando a identidade cultural do povo Karajá 4 .

Diriti vive em Bdè Burè, uma aldeia urbana as margens do rio Araguaia e que sofre os impactos da influência da cidade onde há um turismo gerador de incidência excessiva de barcos, e destruição ambiental. Além disso, a influência do álcool, drogas e prostituição também são fatores de extrema preocupação para a aldeia. ${ }^{5}$

Este trabalho tem por objetivo fazer uma análise de como a feitura da Ritxoko pela indígena Diriti Karajá da aldeia Bdè Burè pode ser identificada como possibilidade de manutenção da cultura de um povo juntamente com a subsistência das mulheres numa perspectiva que visa a desconstrução da ortodoxia imposta pela sociedade brasileira. Para tanto, buscar-se-á elaborar uma discussão sobre a apreensão de sentidos atribuídos à mulher e a natureza a partir do ponto de vista Ecofeminista crítico e a busca de redistribuição e reconhecimento.

Para elaboração deste trabalho, utilizamos basicamente a pesquisa qualitativa, por privilegiar algumas técnicas que coadjuvam com o estudo dos fenômenos sem pressupor a obrigatoriedade de utilização de uma única técnica. A Pesquisa Bibliográfica contribuiu para a construção do trabalho por oferecer meios de conhecer dados já escritos por outros pesquisadores, reforçando as informações. Houve também a contribuição da Observação Participante, obtida pelo contato direto a partir da filmagem do documentário, onde se pôde recolher informações dos atores em seu contexto original, a partir de seus pontos de vista e suas perspectivas.

Diriti, viúva e destituída de bens materiais e simbólicos para interagir com a sociedade urbana traz em sua própria trajetória de luta a detenção do conhecimento sobre o modo de fazer Ritxoko como capital simbólico que possibilita sua subsistência e

\footnotetext{
${ }^{4}$ São representações de formas humanas e também animais da fauna regional sendo pintadas com diferentes grafismos e utilizadas pelas mulheres para a socialização das meninas não somente como brinquedo, mas como representações da família e identidade Karajá.

${ }^{5}$ Depoimento pessoal do Cacique Tohobahi Karajá no dia 12 de julho de 2017 em sua casa na Aldeia Bdè Buré em Aruanã /Goiás.
} 
transmissão da cultura. Capital que carrega em seu bojo um conjunto de memórias e narrativas que transitam nas questões de gênero e etnia.

\section{RELAÇÕES DE GÊNERO, ECOFEMINISMO, REDISTRIBUIÇÃO E RECONHECIMENTO}

As feministas desafiaram a prática de excluir mulheres da cidadania, com o argumento de que as diferenças de sexo não sinalizavam maior ou menor capacidade social, intelectual e política (SCOTT, 2002). A perspectiva feminista tem buscado a redefinição de um conjunto de direitos humanos no século XXI, pois, "o conceito de direitos humanos não é um conceito estático ou propriedade de um só grupo, mais ainda, seu significado se amplia no tempo que a cidadania redefine suas necessidades e seus desejos na relação com eles" (FOLGUERA, 2006, p.89). Combinar a crítica às suposições do discurso pelos direitos com uma permanente contextualização dos direitos nos sistemas de relações sociais especialmente de gênero seria uma saída estratégica política para fazer a constante adequação de direitos no que se refere as mulheres em suas diversas diferenças (JELIN, 1994, p.126).

Para Saffioti (2004), o gênero como um aparelho semiótico ou matriz atribuidora de sentido, faz pensar que a multiplicidade do sujeito apresenta o reconhecimento, aceitação e defesa das diferenças. Portanto,

a tripla constituição do sujeito-gênero, raça/etnia e classe afasta a idéia de sua unicidade. Ao contrário, ele é múltiplo e contraditório, mas não fragmentado. Com efeito, esses três antagonismos constituem um nó que potencia o efeito dessas contradições tomadas, cada um per si, isoladamente. (SAFFIOTI, 2004, p.37)

Com vistas à explicação do conceito de gênero e de como as relações entre os sexos se estruturam, Scott conceitua o gênero como "um elemento constitutivo de 
relações sociais fundadas sobre as diferenças percebidas entre os sexos, e o gênero é o primeiro modo de dar significado às relações de poder" (SCOTT, 1990, p.14).

Este elemento constitutivo das relações de gênero aparece: 1. Nos símbolos culturalmente disponíveis; 2. Nos conceitos que evidenciam as interpretações dos símbolos; 3. Na política e na referência às instituições e à organização social; 4. Na identidade subjetiva historicamente construída (SCOTT, 1990, p.14-5).

Scott propõe a política como um dos domínios de utilização do gênero para a análise histórica, pois para a referida autora, a política constrói o gênero, e o gênero constrói a política. A autora justifica a escolha da política e do poder no sentido mais tradicional, ou seja, referente ao governo e ao Estado-nação, afirmando, em primeiro lugar, que se trata de um território praticamente inexplorado, uma vez que o gênero tem sido percebido como uma categoria antitética às questões sérias da "verdadeira" política.

A segunda questão deve-se a que a política permanece resistindo à inclusão de materiais ou questões sobre as mulheres e o gênero. O aprofundamento da análise dos diversos usos do gênero oferecerá novas perspectivas a velhas questões, redefinirá as antigas em novos termos, e colocará as mulheres como participantes visíveis e ativas trazendo, portanto, possibilidades para a reflexão sobre as estratégias políticas atuais e futuras para as relações de gênero.

Nancy Fraser (2002) propõe uma análise de gênero que abranja toda a gama de causas feministas desde o feminismo socialista onde eram marcadas as questões relativas ao trabalho doméstico, a reprodução e a sexualidade, até as voltadas para identidade ou configuração cultural nos anos 90.

Para evitar que involuntariamente o feminismo se articule ao neoliberalismo, as feministas modernas devem revisitar o conceito de gênero, pois se faz necessário acomodar pelo menos dois tipos de interesse: incorporar por um lado a questão centrada no trabalho e associada ao feminismo socialista e, por outro, acomodar a questão centrada na cultura. 
Para evitar formulações que coloquem essas duas posições como antitéticas, é preciso desenvolver uma explicação de gênero que englobe os interesses de ambas. Isso exige uma teorização tanto sobre o caráter de gênero da economia política quanto sobre a ordem cultural do androcentrismo, sem que qualquer delas se reduza em função da outra. Ao mesmo tempo, duas dimensões analiticamente distintas do sexismo devem ser teorizadas: a distribuição e o reconhecimento. Fraser situa as lutas de gênero como uma das faces de um grande projeto político que busque uma justiça democrática institucionalizante, ao cruzar os múltiplos eixos da diferenciação social, propondo também um conceito de justiça abrangente que seja capaz de englobar igualmente redistribuição e reconhecimento.

Os conceitos propostos são pautados por um diagnóstico mais amplo da atual conjuntura, pois de um lado supõe que gênero faz uma intersecção com outros eixos de subordinação tornando o projeto mais complexo, e por outro, relacionou a abordagem das políticas feministas a uma mudança maior na gramática da formulação das reivindicações "da redistribuição ao reconhecimento" propondo uma orientação política bidimensional. Para Fraser (2002), esta abordagem mantém vivos os insights do marxismo e, ao mesmo tempo, aprende com a virada cultural.

A partir das múltiplas vertentes dos Movimentos Feministas contemporâneos e, na busca de compreender fatores geradores da dominação feminina, surge um movimento chamado de Ecofemismo. Movimento que nas suas mais diferentes interpretações e tendências, tem colaborado ao coligar os debates feministas às questões de preservação e manutenção da vida saudável e digna, em todas as suas formas. Movimentos ecofeministas e ecológicos convergem em vias que além de buscar uma melhor convivência no planeta, traz a necessidade de desconstrução da exploração capitalista e patriarcal do ecossistema e das mulheres (ANGELIN, 2014 p.14).

Manoela Tavares em seu artigo Ecofeminismo(S) elabora um breve histórico ${ }^{6}$ do surgimento do Ecofeminismo mostrando que em 1974 Françoise d'Eaubonne ${ }^{7}$

\footnotetext{
${ }^{6 “} \mathrm{O}$ feminismo chegou aos temas ecológicos já nos anos 60 do século passado. Esse não foi um encontro fortuito. Havia muitos elementos em comum entre a crise ambiental, que se avizinhava com o avanço da industrialização e da urbanização, e a percepção dos movimentos feministas sobre o lugar destinado às mulheres nessas sociedades emergentes. Os problemas decorrentes das guerras e do militarismo e a consciência da exclusão das mulheres do mundo público trouxeram à tona que a sua opressão se
} 
constituía a primeira relação entre ecologia e libertação das mulheres ao afirmar que estas tinham de ter o poder de controlar a sua fertilidade para que, deste modo, se pudesse salvar o planeta da sobrepopulação. Usa-se pela primeira vez a palavra ecofeminismo e assim se constitui um movimento político pela defesa do ambiente e do feminismo, associando a opressão das mulheres à opressão da natureza. $\mathrm{O}$ ecofeminismo tornou-se mais conhecido na conjuntura das lutas contra os resíduos tóxicos, contra centrais nucleares e bases militares

Em Março de 1980 em Amherst nos EUA, ocorreu a $1^{\text {a }}$ Conferência Ecofeminista "Mulheres e vida na terra" onde foi alegado por Ynestra King uma das organizadoras que a destruição da Terra pelas grandes empresas e pelas ameaças nucleares das potências militares era um problema feminista. Buscava-se identificar que a postura de violações sobre a terra teria uma mentalidade masculina que também buscava negar direito às mulheres relativamente ao corpo e à sexualidade estabelecendo uma relação entre a violência patriarcal contra as mulheres e a Natureza.

Em Colónia, na Alemanha em 1987, foi realizado o congresso "Mulheres e Ecologia”, onde Angeline Birk e Irene Stoehr ressaltaram a contradição entre a lógica da emancipação surgida no século das Luzes com a sua grande valorização da Ciência e da Tecnologia e a destruição ecológica. Lembrando assim que o conceito de emancipação conceberia o domínio sobre as mulheres e a natureza.

Em 1992, Carolyn Merchant no livro Radical Ecology: The Search for a Liveable World afirma que o ecofeminismo é mais próximo do feminismo cultural e estabelece uma associação histórica e cultural entre as mulheres e a natureza, considerando assim que estas podem libertar-se a elas próprias e à natureza através do ativismo ambiental. Faz ainda uma associação entre a biologia das mulheres e a natureza como fontes. Associa ainda a biologia das mulheres e a natureza como mananciais de poder para resistir à “tecnologia masculina”. Logo, estavam lançadas as bases para a contestação do ecofeminismo pelo seu essencialismo por parte de outras correntes feministas. Para Flores \&Trevizan (2015),

A relação entre ciência, mulher e natureza estaria entre as primeiras preocupações do movimento ecofeminista. Destaca-se no movimento

reproduzia em outras esferas, inclusive e, sobretudo, nos lares. Daí o lema do feminismo daquele período: o pessoal é político". (SILIPRANDI, 2009, p.141)

${ }^{7} \mathrm{O}$ termo ecofeminismo teria sido utilizado pela primeira vez em 1974, por Françoise d‘Eaubonne, que, em 1978, fundou, na França, o movimento Ecologia e Feminismo (FLORES \& TREVIZAN, 2015, p.12). 
que ecologia é um assunto feminista, mas que as semelhanças entre feminismo e ecologia têm sido esquecidas pela ciência ecológica, e essa vertente do movimento feminista, unindo o movimento das mulheres com o movimento ecológico, traz uma nova visão de mundo, desvinculada da concepção socioeconômica e de dominação. (FLORES \& TREVIZAN, 2015, p.12)

Segundo Souza (2008, p.02) o Ecofeminismo $^{8}$ ao integrar ecologia e feminismo compreende a ideia da opressão das mulheres e a destruição da natureza como duas questões intimamente ligadas, numa lógica que se contrapõe a teoria de gênero que busca desnaturalizar a associação entre mulher, natureza e procriação. Para a autora, no contexto da segunda onda do feminismo, a partir do final dos anos de 1950, o Ecofeminismo recupera as críticas feitas por Beauvoir, sobre a forma biologizante, inferior e irracional que era caracterizada a mulher, porém, trouxe uma nova valorização para a relação feminino/natureza. Para ela,

O Ecofeminismo contando com distintas significações, compõe uma ideia fundamental, que é a existência de uma interconexão entre a dominação da natureza pelos seres humanos e a sujeição feminina aos homens, expressando a predominância de formas patriarcais na estruturação ocidental, que remete o papel da mulher apenas à reprodução social (SOUZA, 2008, p.06)

Pode-se perceber que a proposta do movimento analisa os impactos que as mulheres destituídas de capital material e simbólico sofrem a partir da destruição do meio ambiente e a impossibilidade de relações sociais e exercício de uma cidadania plena. Segundo Siliprandi (2006) a predominância de formas patriarcais na estruturação ocidental, que remete o papel da mulher apenas à reprodução social seria estabelecida porque, como discutem algumas autoras ecofeministas, tanto as mulheres quanto o meio

\footnotetext{
${ }^{8} \mathrm{O}$ Ecofeminismo se apresenta a partir dos movimentos feminista da década de 1970 e receberam contribuições de diversos movimentos antimilitaristas, antinucleares e pacifistas que eclodiram nos EUA e Europa durante 1960, que originaram os movimentos ambientalistas atuais. Caracterizando de forma geral a esses movimentos, Barbara Holland-Cunz identifica a "utopia ecofeminista primitiva" "que se desenvolve através de ações especificas: lutando pela superação da dominação patriarcal nas relações entre os gêneros; procurando por tecnologias que não agridam o meio ambiente; possuindo ideais de democracia direta, descentralização e o fim das hierarquias; e apoiando economias de subsistência rural como modelo de desenvolvimento". (SOUZA, 2008, p.05)
} 
ambiente são vistos pelo patriarcalismo como objetos de consumo e exploração. Assim, para Flores \&Trevizan (2015),

O ecofeminismo identifica no sistema patriarcal a origem da catástrofe ecológica atual, tendo sido a natureza e as mulheres, ambas associadas à reprodução da vida, o alvo das agressões desse sistema. Nessa perspectiva, o patriarcado se exprime com a mesma lógica do poder machista, opressor e totalitário da agroindústria, atacando os fundamentos da vida, na sua expressão simbólica mais profunda: a fecundidade do ser vivo. Daí a luta de feministas pela libertação da mulher oprimida, na relação de gênero, estar associada ao movimento ecofeminista de libertação da mulher e da natureza, ambas exploradas. (FLORES \& TREVIZAN, 2015, p. 12)

Siliprandi (2006) afirma que de forma genérica, o pensamento ecofeminista possui três pressupostos: O primeiro sob o ponto de vista Econômico, no qual se percebe que a mulher e a natureza são tidas como recursos ilimitados que proporcionam a acumulação do capital; O segundo sob o aspecto Político traz a identificação da mulher com a natureza e o homem com a cultura, perpetuando a hierarquização dos segundos (homem e cultura) para legitimar a opressão da mulher e da natureza; E por fim o enfoque Científico e tecnológico, ressalta a exclusão das mulheres do campo científico revelando não haver neutralidade quanto ao gênero no que se refere à atuação científica e tecnológica para o desenvolvimento econômico moderno.

Puleo, (2002,37-9) divide o Ecofeminismo em três tendências:

a) O Ecofeminismo clássico assinala que a tentativa de naturalização da mulher como um dos mecanismos de legitimação do patriarcado juntamente com a obsessão dos homens pelo poder que tem levado o mundo a guerras suicidas, ao envenenamento e à destruição do planeta. Argumenta que neste contexto, a ética feminina de proteção dos seres vivos se opõe à essência agressiva masculina, abalizada por distinções femininas igualitárias e maternais que as predispõe ao 
pacifismo e à conservação da natureza, enquanto os homens seriam naturalmente propensos à competição e à destruição;

b) O Ecofeminismo espiritualista do Terceiro Mundo é originário dos países do sul, sob a influência dos princípios religiosos de Ghandi, na Ásia, e da Teologia da Libertação, na América Latina. Esta tendência assevera que o desenvolvimento da sociedade gera um processo de violência contra a mulher e o meio ambiente, tendo portanto suas raízes nas concepções patriarcais de dominação e centralização do poder. Caracteriza-se também pela atitude crítica contra a dominação, pela luta relativa a raça, classe, gênero e etnia. Esta vertente traz Vandana Shiva como representante da cosmologia Hindu e vinculada as tendências místicas do ecofeminismo primordial, como realizadora de uma séria crítica do desenvolvimento técnico ocidental que tem colonizado o mundo todo, e por ser fonte de violência contra a mulher e natureza tendo suas raízes em postulados patriarcais de homogeneidade, dominação e centralização que fundamentam as estruturas de pensamento e estratégias de desenvolvimento dominante, chamado por ela de mal desenvolvimento. Em seus livros pode-se perceber que existem movimentos de resistência ${ }^{9}$ ao mal desenvolvimento, embora os meios de comunicação silenciem. $\mathrm{Na}$ América Latina ${ }^{10}$, com a Teologia da libertação tem início a elaboração de um pensamento teológico ecofeminista que privilegia seu interesse às mulheres pobres, e na defensa dos povos indígenas vítimas da destruição da natureza.

c) No Ecofeminismo construtivista há uma divergência relativa às tendências anteriores, não se identificando nem com o essencialismo, nem com as fontes religiosas espirituais das correntes anteriores embora compartilhem, de acordo com os casos, algumas de suas posições como antirracismo, antiantropocentrismo e anti-elitismo.

\footnotetext{
${ }^{9}$ Um dos movimentos de resistência ao mal desenvolvimento é o das mulheres Chipko do qual Vandana Shiva é porta-voz. Estas mulheres influenciadas pelo princípio feminino da natureza da cosmologia da Índia e da não-violência influenciada por Gandhi conseguiram deter o desmatamento total do Himalaya, adquiriram consciência de grupo e continuaram lutando contra a violência doméstica e pela participação política (PULEO, 2002, p.38).

${ }^{10}$ No Brasil, Ivone Gebara sustenta que falar de justiça social atualmente, implica necessariamente falar de ecojustiça (PULEO, 2002, p. 38).
} 
Defende que a relação da maioria das mulheres com a natureza é desconexa a características próprias do sexo feminino, mas oriunda de suas responsabilidades de gênero na economia familiar, cunhadas por meio da divisão social do trabalho, da distribuição do poder e da propriedade. Bina Agarwal é um exemplo de feminista Constructivista com formação em Economia, que embora seja também da India critica Vandana Shiva por esta atribuir a atividade protetora da natureza das mulheres do seu país para o princípio feminino de sua cosmologia.Para Agarwal, o vínculo que algumas mulheres sentem com a natureza decorre de suas responsabilidades na economia familiar. Pensam de forma holística e em termos de prioridade comunitaria e realidade material em que se encontram. Não são características afetivas ou cognitivas proprias de seu sexo, mas a sua interação com o ambiente que favorece a sua consciência ecológica. A sensibilidade ou não com o meio ambiente decorre da divisão sexual do trabalho e das divisões de poder e propriedade de acordo com a classe, gênero, raça e também de casta. Val Plumwood, filosofa australiana e crítica construtivista tem insistido no caráter histórico, construído da racionalidade masculina dominadora e na necessidade de superação dos dualismos hierárquicos como natureza / Cultura, mulheres / homens, Corpo / razao /emoção, matéria / espírito.

Para Flores \& Trevizan, (2015, p. 12) as referidas tendências ainda que partam de pressupostos conflitantes, de forma particular na abordagem clássica e a construtivista, presume-se, nas três, uma forte relação entre mulher/feminilidade - natureza, mais intensa do que a relação homem/ masculinidade-natureza, perpetrando a mulher como mais cautelosa. Ressaltam que,

o que difere nas três abordagens é a origem dessa relação: enquanto na tendência clássica a explicação das diferenças está na própria natureza do homem/masculino ser agressivo e destrutivo, na tendência espiritualista, a explicação das diferenças encontra-se no processo do desenvolvimento "selvagem", que teria descuidado da finitude e capacidade de resiliência da natureza, e, na tendência construtivista, a explicação é cultural, produto da divisão social do trabalho e de uma estrutura social marcada pela desigualdade. (FLORES \& TREVIZAN, 2015, p. 12) 
Lembram os autores em referência que não obstante as tendências espiritualista e construtivista recusem a relação de gênero com o meio ambiente como um fenômeno natural, como incide na abordagem clássica, nas três, independentemente do discurso de cada abordagem com seus mitos e realidades, todas aceitam haver uma forte relação do ecofeminismo com a proteção do meio ambiente.

Importante lembrar que tanto as mulheres quanto a natureza são categorias socialmente construídas, podendo ser alteradas em cada condição dada. Afirmar que as mulheres possuem conexão especial com a natureza "não permite perceber que tanto elas quanto os homens das diferentes sociedades podem olhar e experimentar as coisas de diversas formas, até porque as relações das mulheres com a natureza variam segundo a classe, a raça, a etnia, a nacionalidade, a idade, entre outros aspectos" (HERNANDEZ, 2010, p.23).

\title{
3. DIRITI DE BDÈ BURÈ E O ECOFEMINISMO
}

Em relação ao ecofeminismo em sua tendência construtivista, Siliprandi, (2009) ressalta que, esta

\begin{abstract}
tenta recuperar tanto a análise das condições concretas de vida das mulheres como os condicionantes ideológicos integrantes do sistema sexo-gênero que marcam a construção das subjetividades masculina e feminina e que devem ser desmontados para poder se avançar em direção a propostas de transformação social ecologistas e com igualdade de gênero. (SILIPRANDI, 2009, p.142)
\end{abstract}

Assim, a necessidade da organização da mulher enquanto sujeito político que tem especificidades nas lutas sociais e, nas questões ambientais, contemplando-se da mesma forma os demais sujeitos coletivos oprimidos, são propostas da tendência construtivista que ainda retoma a linguagem dos direitos e da igualdade como norteadora dessa luta, não permitindo nenhum espaço para qualquer tipo de essencialismo ontologizante.

Importante lembrar que embora o fazer Ritxoko seja possibilidade e responsabilidade exclusiva das mulheres Karajá, não se pode entender a relação da mulher com a natureza como uma característica intrínseca do sexo feminino, mas 
derivada da responsabilidade de gênero resultante da divisão social do trabalho, da desigual distribuição do poder intra e extra etnia.

A tendência construtivista pode ser compreendida para se pensar a estratégia de luta da indígena. Luta que pode ser percebida na postura de Diriti pelo fazer Ritxoko no qual tem um capital social fundamental para o desenvolvimento de sua vida individual na busca de sua própria subsistência econômica, por um lado; e por outro, na medida em que esta postura altera também a própria coletividade ao transmitir saberes que mantém a cultura preservada, trazendo uma relação entre ecofeminismo e sustentabilidade ambiental.

Pode-se perceber que como pressuposto de existência de prática sustentável o uso do barro ${ }^{11}$ se impõe relativamente a preservação dos recursos uma vez que embora Diriti tenha passado a vida fazendo Ritxoko, a noção de duração do tempo e de um desenvolvimento que não esgota os recursos para o futuro está associado às condições de vida da indígena e sua comunidade. Questões que podem ser percebidas a partir dos princípios de ecodesenvolvimento de Inacy Sachs (2008) ao relacionar satisfação das necessidades; solidariedade com as gerações futuras; participação da população envolvida e preservação dos recursos naturais.

Mesmo diante de posturas autoritárias do governo brasileiro relativamente as questões indígenas impedindo a justiça paritária que devem ser construídas a partir da redistribuição e reconhecimento (FRASER, 2002), em Diriti Karajá pode-se perceber elementos de resistência que determina o continuísmo cultural e o ritual que define a identidade enfrentando assim a ortodoxia proposta pelo Estado e sociedade.

Cabe lembrar que, de um lado, as posturas autoritárias do Estado aparece como pólo dominante que com capital específico inclina-se para estratégias de conservação que correspondem à defesa da ortodoxia; e de outro, o pólo dominado com menor poder de capital volta-se para as práticas heterodoxas, pois procura manifestar sua insatisfação por meio de estratégias de subversão.

\footnotetext{
${ }^{11} \mathrm{O}$ documentário Diriti de Bdè Burè mostra a indígena descendo o Rio Araguaia em busca do barro apropriado para a feitura da Ritxoko. Porém é importante lembrar que atualmente por causa da idade e também pelas condições do próprio rio, ela compra o barro já preparado na Cidade de Goiás.
} 
Assim, cabe lembrar que as estratégias de subversão se dão dentro da estrutura do campo que está sempre em luta, já que os agentes sociais, ao adotarem estratégias de conservação ou de subversão, determinam uma nova distribuição do capital dentro do campo. Para se compreender a lógica social de um campo, é preciso apreender o que faz a necessidade específica da crença que lhe dá suporte, do jogo de linguagem que se joga, das coisas materiais e simbólicas que estão em jogo (BOURDIEU, 2000, p. 69).

A proposta heterodoxa de Diriti de Bdè Burè dá-se por duas perspectivas simultâneas qual seja uma composição individual na medida em que se busca a partir de sua capacidade de ação e decisão nos processos de manutenção de sua cultura, conjuntamente com uma composição social que garante a manutenção do poder criativo das gerações futuras e a circulação da ritxoko como estratégia de divulgação da cultura do povo Karajá.

\section{CONCLUSÃO}

As mulheres indígenas vivenciam as consequências de suas situações sociais numa sociedade que as discrimina por sua condição geral de pobreza dentro de uma perspectiva de raça e etnia.

A Ritxoko como manifestação cultural e produto comercializável contribui para com os processos comunitários de valorização dos saberes e práticas culturais. Diriti ao valorizar e transmitir os saberes sobre o uso do barro e seu manejo valoriza sua comunidade, mantem suas necessidades de subsistência e ainda contribui para o reconhecimento do trabalho das mulheres Karajá. Divulga a cultura indígena e faz aumentar a fonte de renda para si e para a comunidade numa insistente estratégia de luta pela reconhecimento e pela redistribuição.

Bourdieu reconhece a possibilidade de se efetuar uma transferência de capital cultural, pois o dominado pode buscar a mobilização coletiva e a ação subversiva contra a ordem estabelecida. Para que isso ocorra, seria necessário para se libertar de níveis da dominação, denunciar a arbitrariedade que escamoteia a realidade. Mas a questão que se coloca é que, esta crítica pressupõe mecanismos que, como as outras formas de capital, estão distribuídos assimetricamente e é exatamente esta 
desconstrução que tem buscado o movimento feminista em sua tendência ecofeminista construtitivista que pode ser percebida na postura de luta de Diriti de Bdè Burè.

\section{REFERÊNCIAS BIBLIOGRÁFICAS}

ANGELIN, Rosângela. Mulheres, ecofeminismo e desenvolvimento sustentável diante das perspectivas de redistribuição e reconhecimento de gênero. Estamos preparados?. Revista Eletrônica Direito e Política, Programa de Pós-Graduação Stricto Sensu em Ciência Jurídica da UNIVALI, Itajaí, v.9, n.3, 30 quadrimestre de 2014. Disponível em: www.univali.br/direitoepolitica - ISSN 1980-7791.

Gênero e meio ambiente: a atualidade do ecofeminismo. 2008. Disponível em: http://www.espacoacademico.com.br/058/58angelin.htm. Acesso em: 17 de maio de 2016.

BOURDIEU, Pierre. A dominação masculina. Rio de Janeiro: Bertrand Brasil, 1999.

O poder simbólico. Rio de Janeiro: Ed. Bertrand Brasil, 2000.

FLORES, Bárbara Nascimento; TREVIZAN, Salvador Dal Pozzo. Ecofeminismo e comunidade sustentável. Rev. Estud. Fem., Florianópolis, v. 23, n. 1, p. 1134, Apr. $2015 . \quad$ Available from <http://www.scielo.br/scielo.php?script=sci_arttext\&pid=S0104-

026X2015000100011\&lng=en\&nrm=iso>.

Access on 11 Aug. 2017. http://dx.doi.org/10.1590/0104-026X2015v23n1p/011.

FOUGUERA, Pilar. La equidad de gênero en el marco internacional y europeo. In: Del Vale, Teresa. Mujeres, globalización y derechos humanos. Madrid: Edições Cátedra, 2006.

FRASER, Nancy. Políticas feministas na era do reconhecimento: uma abordagem bidimensional da justiça de gênero. In: BRUSCHINI, Cristina \& UNBEHAUM, Sandra G. (org) Gênero, democracia e sociedade brasileira. São Paulo: Fundação Carlos Chagas/Editora 34, 2002.

GEERTZ, Clefford. A interpretação das culturas. Rio de Janeiro:LTC,1989.

HERNANDEZ, Carmen Osorio. Gênero e Meio Ambiente: A construção do discurso para o Desenvolvimento Sustentável. In: Ambiente y desarrollo, Bogotá (Colombia), Volumen XIV No. 26, enero-junio de 2010.

JELIN, Elizabeth. Mulheres e direitos humanos. Estudos Feministas. Vol 2, n.3 Rio de Janeiro: 1994. p.117-49.

SACHS, Ignacy. Desenvolvimento: includente, sustentável, sustentado. Rio de Janeiro: Garamond,2008.

Revista de Gênero, Sexualidade e Direito | e-ISSN: 2525-9849 | Maranhão | v. 3 | n. 2 | p. 137 - 152 | 
SAFFIOTI, Heleieth. I. B. Gênero, patriarcado e violência. São Paulo: Editora Fundação Perseu Abramo, 2004.

SCOTT, Joan. A cidadã paradoxal: as feministas francesas e os direitos do homem. Florianópolis: Editora Mulheres, 2002.

SILIPRANDI, E. Ecofeminismos: mulher, natureza e outros tipos de opressão. Encontro Fazendo Gênero 7 - Simpósio Temático n.31. UFSC Florianópolis, 2006.

.Um olhar ecofeminista sobre as lutas por sustentabilidade no mundo rural. In:PETERSEN, Paulo (Org). Agricultura familiar camponesa na construção do future. Rio de Janeiro: AS-PTA, 2009.

SILVA, Telma Camargo. Modos de fazer Boneca Karajá, circulação de conhecimento e a construção do território. http://nepi.ufsc.br/files/2013/11/PaperTelma-Camargo-da-Silva-NEPI1.pdf (Acessado em 06/08/17)

SORJ, Bila. O FEMININO COMO METÁFORA DA NATUREZA. Estudos Feministas, Florianópolis, v. 0, n. 0, p. 143, jan. 1992. ISSN 1806-9584. Disponível em: <https://periodicos.ufsc.br/index.php/ref/article/view/15806/14299>. Acesso em: 10 ago. 2017.

SOUZA, Iriê Prado de; RAMÍREZ-GÁlVEZ, Martha Celia. Os sentidos e representações do ecofeminsimo da contemporaneidade. In: DONAT, Miriam, IVANO, Rogério. Anais do VII SEPECH (Seminário de Pesquisa em Ciências Humanas). Londrina: Eduel, 2008. p. 4.

PULEO, Alícia H. Feminismo y Ecología. El Ecologista, no 31, Verano, 2002.

TAVARES,

Manoela.

Ecofeminismo

(S).

http://www.cdocfeminista.org/index.php/pt/arquivo/66-ecofeminismo-s (acessado em 07/08/2017) 